\title{
Breve perspectiva historiográfica sobre a ancestralidade da etnia indígena Kaingang
}

Brief historiographic perspective of the ancestry of the indigenous Kaingang ethnic group

\author{
Jéssica da Silva Gaudêncio* \\ Décio Ruivo Martins ${ }^{* *}$ \\ Rosemari Monteiro Castilho Foggiatto Silveira ${ }^{\star * \star}$ \\ Sérgio Paulo Jorge Rodrigues ${ }^{* * *}$
}

Palavras-chave:

Kaingang

História Indígena

Historiografia do Sul do Brasil

Keywords:

Kaingang

Indigenous History

Historiography of Southern Brazil.
Resumo: O objetivo deste artigo é apresentar a historiografia da ancestralidade da etnia indígena conhecida hoje como Kaingang. Antes do século XX, os ancestrais desta etnia foram retratados e citados em várias obras por diversos nomes; porém, nem todos os grupos indígenas referidos na documentação histórica eram Kaingang, o que pode ser verificado pelas características culturais presentes nas documentações de origem. Essa multiplicidade de denominações, além das observações em diferentes regiões geográficas sobre a presença de grupos étnicos com características semelhantes às pertencentes à etnia Kaingang, pode induzir interpretações equivocadas e erradas por pesquisadores. Muitos autores consideram o grupo indígena identificado como Guaianá na literatura da época colonial como os ancestrais da etnia Kaingang. Com base nas pesquisas e em estudos sustentados pelas restritas evidências documentais dos séculos passados, pode-se considerar essa ancestralidade; entretanto, conclui-se que há necessidade de estudos etnográficos com maiores detalhes, para que se possa evidenciar essa proximidade étnica.

Abstract: This article presents the historiography of the ancestry of the indigenous ethnic group known today as Kaingang. Before the XIX century, the ancestors of this ethnic group were depicted with various names and cited in works, but not all the indigenous groups mentioned in the historical documentation were Kaingang, which can be identified by the cultural characteristics present in the original documentation. This multiplicity of denominations groups, as well as the observations in different geographic regions of the presence of ethnic groups with similar characteristics belonging to the Kaingang, can result in erroneous interpretations by researchers. Many authors consider the indigenous group identified as Guaianá in colonial literature as the ancestors of the Kaingang ethnic group. Based on research and studies supported by difficult to access documentary evidence of past centuries, one can consider this ancestry. However, it is concluded that there is a need for ethnographic studies in greater detail, so that this ethnic relationship can be supported with more evidence.

Recebido em 14 de fevereiro de 2019. Aprovado em 15 de março de 2019.

\section{Introdução}

As áreas brasileiras que hoje correspondem aos Estados de Mato Grosso do Sul, São Paulo, Paraná, Santa Catarina e Rio Grande do Sul, além dos países de fronteira, eram abrangidas pelos índios Guarani (conhecidos por Carijó ou Cario na época colonial); porém, não de forma homogênea ou exclusiva (MONTEIRO, 1992a). Os grupos eram encontrados entre os principais rios da região e nas florestas tropicais e subtropicais do litoral. As regiões do Sul do Brasil com maior abrangência de florestas de araucárias (Araucaria angustifólia) eram habitadas por grupos, especialmente de caçadores e coletores, com densidades populacionais relativamente baixas e alta mobilidade sazonal,

\footnotetext{
* Doutoranda em História das Ciências e Educação Científica, Centro de Física da Universidade de Coimbra, Portugal (CEFisUC). E-mail: <jessigaudencio@hotmail.com>.

** Doutor em História e Ensino da Física, Centro de Física da Universidade de Coimbra, Portugal (CEFisUC). E-mail: <decio@uc.pt>.

*** Doutora em Educação Científica e Tecnológica, Programa de Pós-Graduação em Ensino de Ciências e Tecnologia (PPGECT), Universidade Tecnológica Federal do Paraná (UTFPR). E-mail: <foggiattorm@hotmail.com>.

****Doutor em Química, Departamento de Química da Universidade de Coimbra (FCTUC), Portugal. E-mail: <spjrodrigues@ci.uc.pt>.
} 
sendo estes os ancestrais da etnia indígena hoje conhecida como Kaingang.

Atualmente, vivem em Terras Indígenas, localizadas nos estados do Rio Grande do Sul, Santa Catarina, Paraná e São Paulo. De acordo com Mota (2004), a população Kaingang é a mais populosa do Sul do Brasil, e está entre os mais numerosos povos indígenas do país. Estima-se uma população de 45.620 pessoas a viver em mais de 40 Terras Indígenas, conforme o Sistema de Informação da Atenção à Saúde Indígena (SIASI, 2014). Esta etnia indígena pertence à família linguística Jê, do tronco Macro-Jê, e a palavra Kaingang deriva da palavra "caên-gagn" - que em português significa "índio Kaingang", "gente", "pessoa", "gente do mato" (SOUZA, 2014). Franz Keller, em 1867, escreveu um manuscrito sobre os índios da província do Paraná, e registrou que os próprios indígenas se autodenominavam Kaingang. Segundo Keller (1867 apud MOTA, 2004, p. 9) "a si mesmo dão hoje o nome de caên-gagn".

O historiador português Gabriel Soares de Souza viajou para o Brasil entre os anos de 1565 e 1569 , e publicou relatos da sua convivência com os índios durante a sua experiência como senhor de engenho e sertanista; nesta época, o trabalho escravo era composto por índios dos sertões circunvizinhos. Segundo Gabriel de Souza (1851, p. 375-409), a expressão Tupi quer dizer "tio", assim, Tupi-mbá (Tupinambá) significa "tio boa gente", Tupi-aem (Tupinaé) o "tio mau", e Tupiikis (Tupiniquin) o "tio contíguo" ou o "Tupi do lado". Estas definições são importantes para fazer interpretações dos textos mais antigos encontrados na literatura, em que muitas vezes se referem aos Tupinambás e Tupiniquins.

De início, Gabriel Soares de Souza estabeleceu uma divisão entre dois grupos indígenas: os Tupi (Tupinambá, Tupiniquin) e os Tapuia, com descrições opostas entre eles como pode ser observado nos trechos ${ }^{1}$ :

O Tupiniquin [...] É gente de grande trabalho e serviço, e sempre nas guerras ajudaram aos Portuguezes, contra os Aimorés, Tapuias, e Tamoios, como ainda hoje fazem esses poucos que se deixaram ficar junto do mar e das nossas povoações, com quem vizinham muito bem, os quaes são grandes pescadores de linha, caçadores e marinheiros, são valentes homens, caçam, pescam, cantam, bailam, como os Tupinambás, e nas cousas de guerra são mui industriosos, e homens para muito, do quem se faz muita conta a seu modo entre o gentio. (SOUZA, 1851, p. 69).

Como os Tapuias são tantos e estão tão divididos em bandos, costumes e linguagem, para se poder dizer delles muito, era necessário de propósito e de vagar tomar grandes informações de suas divisões, vida e costumes; [...] São os Tapuias contrários de todas as outras nações do gentio, por terem guerra com elles ao tempo que viviam junto do mar, donde por força de armas foram lançados: os quaes são homens de grandes forças, andam nus como o mais gentio, e não consentem em si mais cabellos que os da cabeça, e trazem os beiços furados e pedras nelles, como os Tupinambás. (SOUZA, 1851 , p. 350-351).

Escritores quinhentistas retrataram os grupos Tapuia como a antítese da sociedade Tupi, utilizando, na maioria das vezes, termos negativos para descrevêlos. Este binômio facilitava a compreensão da diversidade linguística e étnica, tanto para os escritores quanto para a coroa. Porém, no contexto do século XIX, historiadores deram um novo sentido para esses dois grupos. Os Tupi passaram a ser os indígenas que contribuíram de maneira heroica, com base nas alianças políticas e matrimoniais à consolidação da presença portuguesa, sendo retratados de maneira romântica e nostálgica. Já os Tapuia eram retratados como inimigos dos portugueses, representavam os índios selvagens, pois se tornaram um obstáculo para a sua civilização, diferentemente dos nobres guerreiros Tupi, que se submeteram ao domínio colonial (MONTEIRO, 2001).

$\mathrm{O}$ pintor holandês Albert Eckhout, que pertencia à corte de Maurício de Nassau (Governador do Brasil Holandês de 1637-1644), pintou quatro quadros a óleo que representam o senso comum da época, de que o indivíduo Tupi era o "domesticado", mostrado na pintura com as vestimentas de pano europeu, e a sua produção de redes e cestos para os estabelecimentos coloniais (Figura 1 (a) e (b)). Já os Tapuia são representados na obra como "selvagens", com ferocidade irredutível, carregando pés e mãos decepados (Figura 1 (d)), o que insinua a antropofagia, rodeados de animais peçonhentos (Figura 1 (c)) como uma cobra jiboia (Boa constrictor), uma aranha caranguejeira (Theraphosidae) e uma taturana (Lonomia obliqua). 

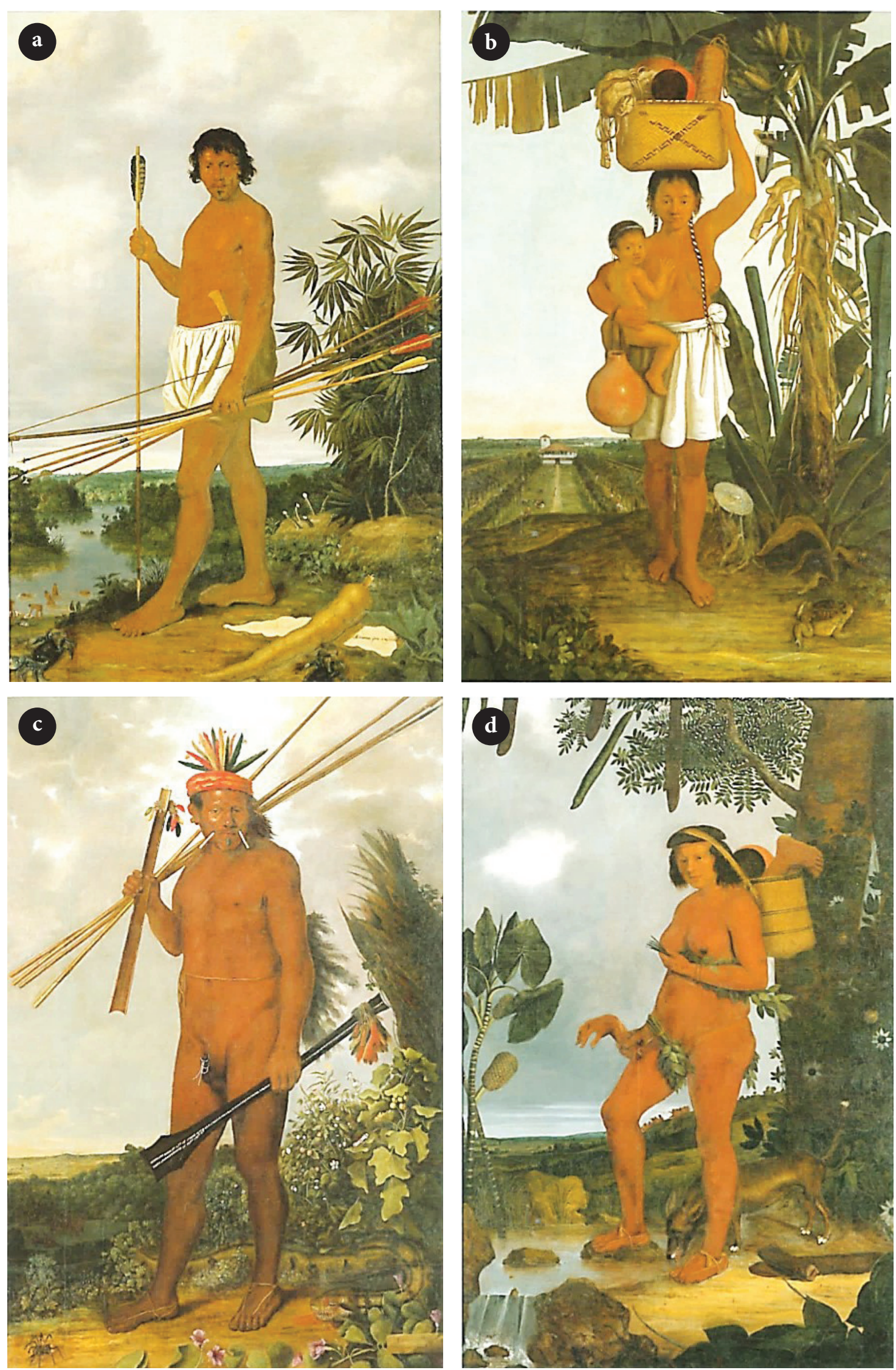

Figura 1: Obras de Albert Eckhout, óleo sobre tela: a) Tupimand - Homem Tupi, 1643, 280 x $176 \mathrm{~cm}$; b) Tupikvinde - Mulher Tupi, 1641, 285 x $173 \mathrm{~cm}$; c) Tapuyamand - Homem Tapuia, 1641, 284 x 176 cm e d) Tapuyakvinde - Mulher Tapuia, 1641, 285 x $173 \mathrm{~cm}$.

Fonte: National Museum of Denmark (2002). 
O nome Bugre foi outra expressão usada no sentido de fazer a diferenciação dos Tupi com os não Tupi, representando aqueles indígenas que resistiam em deixar a mata e serem colonizados, diferentemente dos Guarani que trabalhavam nas fazendas e prestavam alguns serviços (DORNELLES, 2011). Segundo Guisard (1999), o termo Bugre surgiu na Bulgária, no século IX, e corresponde a uma corrente religiosa chamada bogomilismo, inspirada no nome do Padre Bogomil, considerado o fundador desta seita, que, na época, foi perseguida por heresia pela igreja católica. Por isso, no final do século XVIII e início do XIX, quando muitos imigrantes europeus chegavam ao Sul do Brasil, deparavam-se com os nativos e suas tradições e línguas não europeias, e os consideraram "hereges" - assim como os seguidores do bugomilismo -, chamando-os, então, de "búlgares ou bugres".

Entretanto, para o historiador Varnhagen $(1877$, p. 18) a palavra "Bugre não quer dizer mais que carregador ou portador de carga, de Bohu-rêa; como ficaram assim chamados os índios escravos". Já Lague (1983, p. 7-8) diz que a palavra Bugre teve origem no momento de encontro dos primeiros portugueses com os indígenas, que, quando foram vistos, fizeram um sinal de alerta para os demais pertencentes da tribo com um grito agudo, que pareceu ouvir-se a palavra "bugre"; porém, a palavra que gritavam era "pucri”, no qual prolongavam a última sílaba.

Neste contexto de descrição dos indígenas Tapuia e da denominação Bugre, os índios ascendentes da etnia indígena hoje identificada como Kaingang, epouco conhecida com esta denominação nos tempos coloniais, são identificados na literatura (SOUZA, 2012, p. 9; MONTEIRO, 2001, p. 151-182; PINHEIRO, 1992, p. 57; SAINT-HILAIRE, 1964, p. 35) como pertencentes ao grupo Tapuia, sendo também denominados Bugres, e eram retratados sempre como índios "selvagens". Porém, existe uma discussão sobre a ancestralidade desta etnia, pois vários documentos manuscritos da era colonial retrataram os indígenas da região Sul de modo generalista ou com denominações equivocadas. Diante disso, busca-se apresentar resumidamente, alguns relatos e registros presentes na literatura sobre a ancestralidade desta etnia indígena.

\section{A ancestralidade Kaingang}

Antes do século $\mathrm{XX}$, os ancestrais da etnia Kaingang foram retratados e citados em obras coloniais por diversos nomes. Hans Staden, em 1557, cita uma nova denominação para indígenas presentes na região mais ao Sul do Brasil ao descrever a cadeia montanhosa do relevo brasileiro chamada de Serra do Mar: "na serra habita uma casta de selvagens que se chama Wayganna. Estes não têm habitações fixas como os outros, que moram deante e por detraz da serra" (STADEN, 1930, p. 133). Uma grande variação de denominações foi atribuída aos ancestrais Kaingang na literatura colonial e mesmo depois, como pode ser observado no Quadro 1.

Quadro 1: Denominações que fazem menção aos ancestrais Kaingang citadas na literatura.

\begin{tabular}{|c|c|c|}
\hline Denominações & Autor & Ano \\
\hline Wayganna & Hans Staden & 1557 \\
\hline Goainá, Goainazes, Guaianazes, Goayanas & Gabriel Soares de Souza & 1587 \\
\hline Camperos, Cavelludos, Coronados, Gualachos & Nicolas Mastrillo Duran & 1628 \\
\hline Gualachos, Ybiraiyras, Chiquis, Chequis & Antônio Ruiz de Montoya & 1628 \\
\hline Guñanás, Pinares & Juan de la Cruz Cano y Olmedilla & 1775 \\
\hline Guayanás, Guaianás & Padre Manuel Aires de Casal & 1817 \\
\hline Coroados, Guaianás, Bugres & August Saint-Hilaire & 1820 \\
\hline Caveres, Tac-Taia & Padre Francisco das Chagas Lima & 1821 \\
\hline Camés, Votorões, Dorins, Jacfé & Padre Francisco das Chagas Lima & 1842 \\
\hline Guayanazes & José Joaquim Machado de Oliveira & 1846 \\
\hline Caen-gagn & Camilo Lellis da Silva & 1849 \\
\hline Guanhanás & August Saint-Hilaire & 1851 \\
\hline Kaingangues & Juan Ambrosetti & 1894 \\
\hline Cainguangue, Caingang & Von Ihering & 1904 \\
\hline Kaingang & Telêmaco Borba & 1908 \\
\hline Botocudos de Santa Catarina e Paraná & Curt Nimuendajú & 1946 \\
\hline
\end{tabular}

Fonte: Adaptado de Veiga (1994, 2000). 
Outra fonte documental da identificação de diferentes denominações para a ancestralidade dos indígenas Kaingang é a cartografia, por exemplo, o mapa geográfico de América Meridional de 1775 (Figura 2), desenhado por Juan de la Cruz Cano de Olmedilla. Neste mapa, pode-se verificar na região Sul do Brasil a identificação de denominações genéricas para os grupos Kaingang, como Guñanàs e Pinares, esta última atribuída ao fato de ocuparem regiões predominantes de pinheiros. Já a região "Biturunas" indicada no mapa, relaciona-se ao grupo indígena da etnia Xokleng (D’ANGELIS, 2006; HELM, 1995).

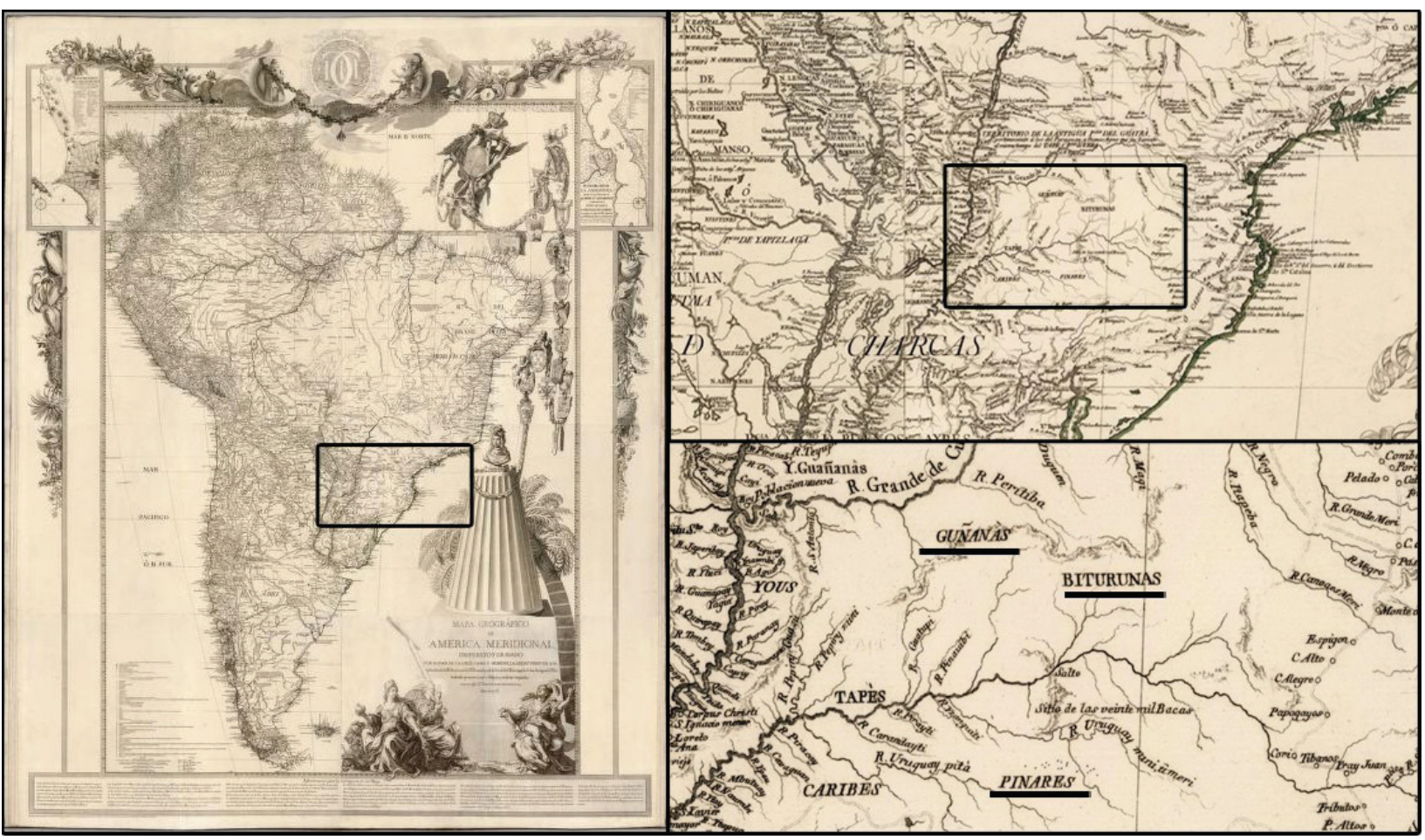

Figura 2: Mapa geográfico de América Meridional Fonte: Olmedilla (1775).

É importante reforçar que nem todos os grupos indígenas referidos na documentação histórica eram Kaingang. Isso pode ser identificado pelas características culturais presentes nas documentações de origem. Essa multiplicidade de denominações, além das observações em diferentes regiões geográficas sobre a presença de grupos étnicos com características semelhantes pertencentes à etnia Kaingang, pode induzir a interpretações equivocadas e erradas por pesquisadores. Outro ponto a ser observado é que alguns grupos desses descritos no Quadro 1 podem não estar relacionados aos Kaingang, mas aos Guarani, Xetá ou Xokleng, grupos que também são identificados pela luta e resistência contra a presença de europeus nas terras do Sul do Brasil (VEIGA, 2000).
A grafia do termo Kaingang pode ser encontrada de diferentes maneiras ao longo da história de contato com o homem branco e as instituições sociais não indígenas. Portanto, o termo aparece escrito em documentos jurídicos e históricos nas seguintes grafias: Kanhgág, Caingang, Caingangue, Kaingang, Kaingangue e Kaingáng. Devido à Convenção para a Grafia de Nomes Indígenas realizada em 1953, a grafia Kaingang passou a ser adotada, e a letra " $\mathrm{C}$ " do Caingang foi substituída pela letra " $K$ " com o objetivo de uniformizar a escrita em português dos nomes das sociedades indígenas brasileiras (SOUZA, 2012).

O nome Bugre que, como descrito anteriormente, indicava osíndios selvagens, também foi muito utilizado na literatura para representar os índios da região Sul do Brasil. Segundo Dornelles 
(2011) e Hicks (1966), os Bugre do Sul foram divididos em dois grupos predominantes na região: os Bugre Coroado (ascendentes da etnia Kaingang) e os Bugre Botocudo (ascendentes da etnia Xokleng), ambos representados na Figura 3 do pintor alemão Philip Schmid.

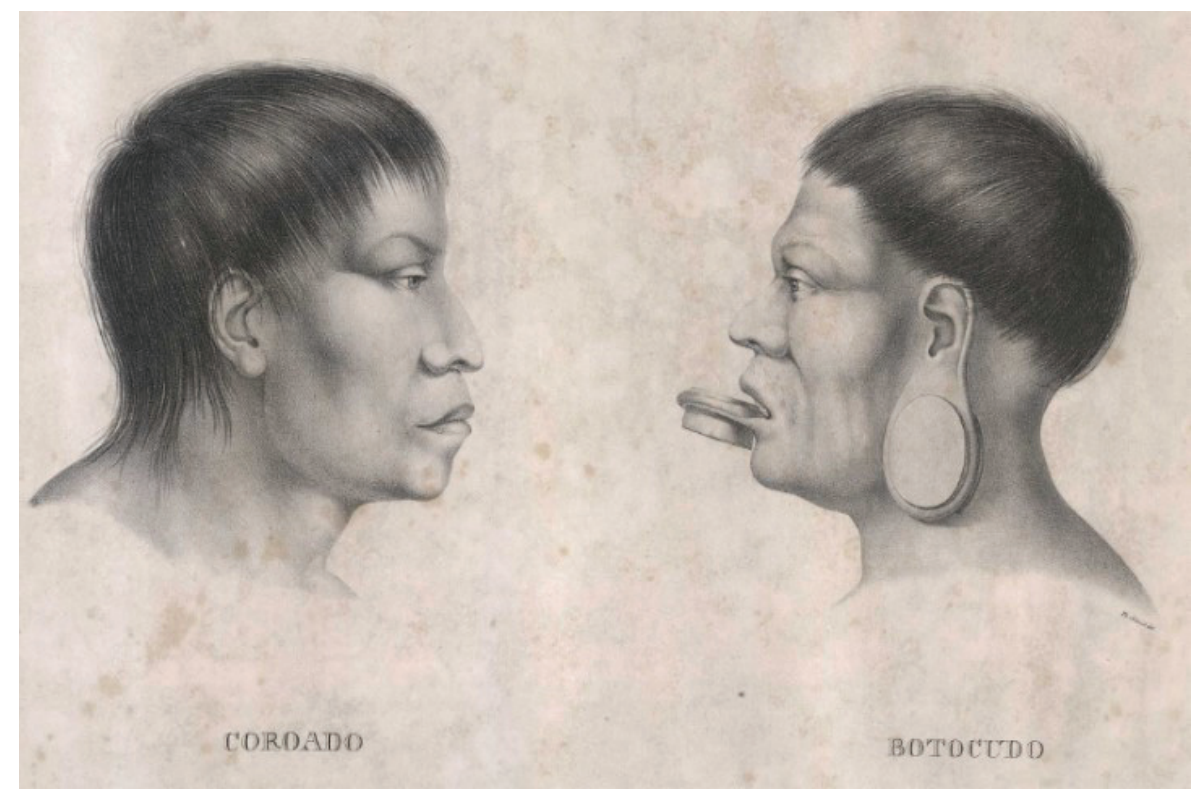

Figura 3: Coroado e Botocudo Fonte: Schmid (1823-1831).

Curt Nimuendajú (1946, p. 93) fez referência aos Botocudo da região Sul, chamandoos de "Botocudos de Santa Catarina e parte adjacente do Paraná", considerando-os relacionados aos índios da etnia Kaingang; porém, diferentes em relação à fala ou cultura. O termo Botocudo foi amplamente utilizado na identificação de diversos grupos indígenas brasileiros, mas sem a definição dos nomes de suas tribos. Estes eram chamados Botocudo devido ao uso de botoques no rosto, como descrito no livro "A Corografia Brazilica ou Relação historico-geografica do Reino do Brazil: composta e dedicada a Sua Magestade fidelissima", em 1817, pelo Padre Manuel Aires de Casal:

[...] de muitos tempos para cá quazi não tem outro nome entre os Christãos senão o de Botocúdos, pelo extravagante,

e ridículo costume de, furarem as orelhas, e os beiços e dilatarem-nos notavelmente com rodellas de páu, parecendo-lhes que ficam assim mais gentis e airozos. Andam sempre de côrso em busca de caça, e das frutas silvestres, seu alimento ordinário, repartidos em malócas de quarenta a sessenta famílias. Algumas tingem o corpo ora de vermelho, ora d'amarello, parecendo carregados de ictyricia: e para se livrarem das ferroadas dos mosquitos nas estações, ou lugares em que elles mais os incommodam, invernizam a pelle com o leite de certas arvores. (CASAL, 1817, p. 72-73).

Neste trecho, Padre Casal descreve o costume dos índios Botocudo ao enfeitarem-se com ornamentos de madeiras em seu rosto (Figura 4) e também sobre suas pinturas corporais fazendo uma comparação da coloração amarela com icterícia. 


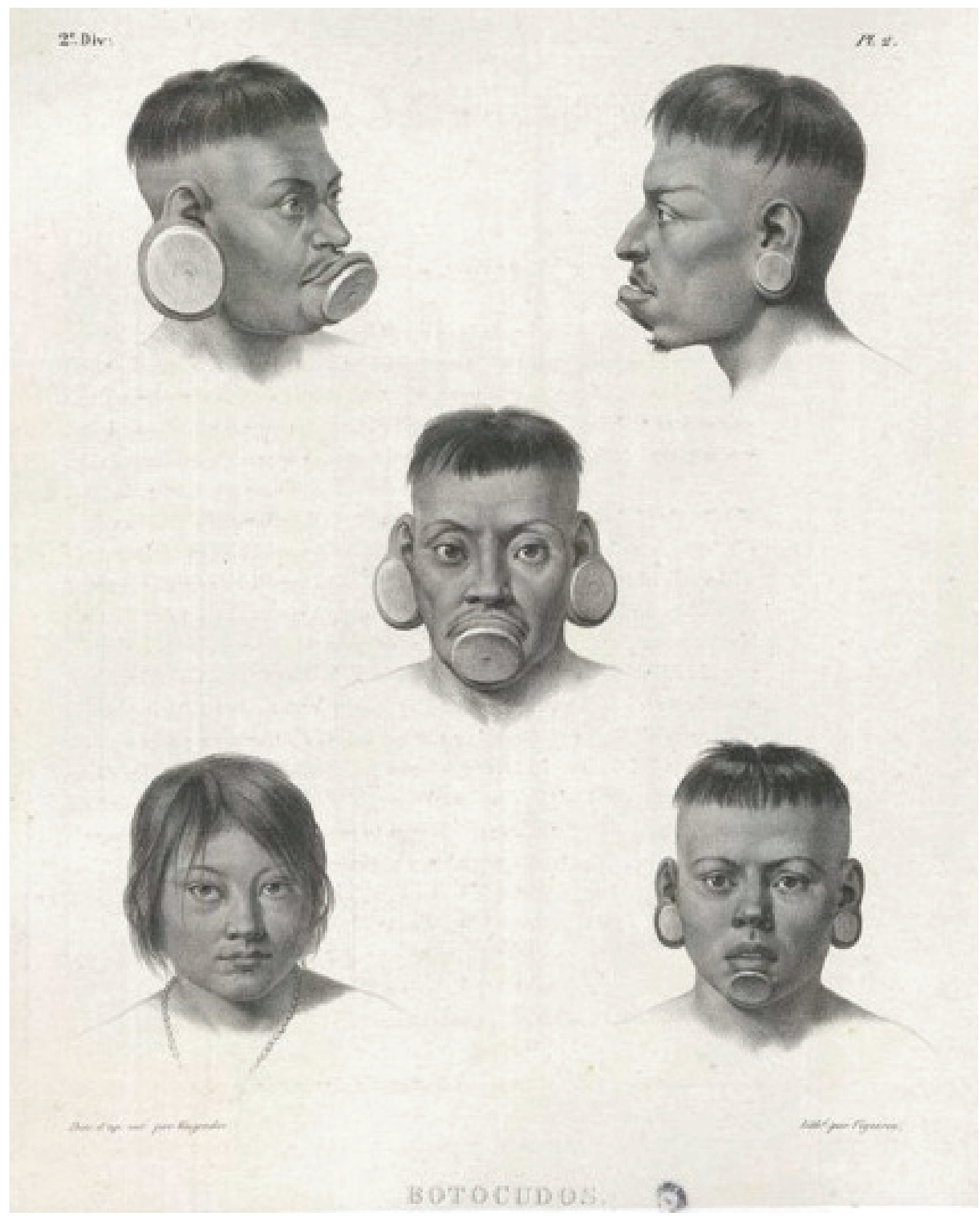

Figura 4 : Representação dos índios Botocudos

Fonte: Vigneron (1835).

Em 1816, o príncipe renano Maximiliano Alexander Philipp de Wied-Neuwied (com o pseudônimo de Max von Braunsberg) escreveu o livro "Viagem ao Brasil" (NEUWIED, 1940), no qual relata seu estudo sobre a fauna, a flora e as tribos indígenas brasileiras, dando destaque aos Botocudo de Jequitinhonha (região Sudeste do Brasil). Segundo Emmerich e Monserrat (1975), 
este livro serviu de fonte para outros autores, e a partir disto, os Botocudo passaram a ter uma ampla documentação, e o termo Botocudo passou a definir apenas o grupo de forma genérica.

Auguste de Sant-Hilaire, um botânico, naturalista e viajante francês, também relatou a presença desses dois grupos de índios designados Bugres Coroados e Botocudos durante suas expedições em território brasileiro. No seu livro "Viagem a Comarca de Curitiba", de 1820, cita:

Além da tribo dos coroados, havia nas vizinhanças de Jaguariaíba muitas outras que frequentemente se guerreavam entre si. A índia coroada do coronel Luciano Carneiro [...], segundo ela me dissera, não longe de sua aldeia existiam selvagens ferozes que também tinham o costume de furar o lábio inferior e as orelhas. Possivelmente, não pertenciam os últimos à mesma nação dos verdadeiros botocudos do Jequitinhonha e do rio doce; mas talvez fossem irmãos dos índios que os paulistas encontraram, em 1845, no Guairá, e aos quais denominaram Botocudos, pela circunstância de usarem no lábio inferior botoques feitos de certa resina que tinha a cor e a transparência do âmbar (SAINTHILAIRE, 1964, p. 47).

Neste trecho o autor relata a presença do grupo Coroado na região do Paraná (Jaguariaíva) juntamente com o grupo Botocudo, mas identificando que este último era diferente do Botocudo da região Sudeste (Jequitinhonha e Rio Doce no Estado de Minas Gerais). Saint-Hilaire (1964, p. 46) também explica o porquê do nome Coroado: "Os paulistas davam aos bugres das proximidades de Jaguariaíba o nome de coroados, porque, diziam, costumavam fazer no alto da cabeça uma espécie de tonsura, ou coroa", assim como descrito pelo Padre Teschauer:

Oviajanteinglez Knivet, contemporaneo de Gabriel Soarez, não concorda sempre com esta descripção. Attribue, porém, aos Caingang o traço caracteristico, pelo que os modernos Guayaná são reconhecidos descendentes daquelles; cortavam o cabello de maneira que formavam uma como coroa, donde deve-se derivar seu outro appellido Coroados. (TESCHAUER, 1927, p. 38).

A "coroa no alto da cabeça" era um corte de cabelo arredondado, que lembra uma coroa, e era comum até mesmo em outras etnias, e pode ter sido o que levou a denominação Coroados. Segundo Borba (1908), o corte de cabelo assemelha-se à tonsura dos frades, e que tanto os homens e mulheres Kaingang tinham o costume de cortar o cabelo com uma larga coroa no centro.

\section{Seriam os atuais Kaingang descendentes dos antigos Guaianá?}

De acordo com Hermann von Ihering (1904, p. 44), os índios chamados Guaianá seriam os ascendentes dos índios Kaingang, podendo também ser chamados em regiões distintas de: Goyanás, Goianases e Wayanazse, sendo citados nos mapas e fontes escritas anteriores ao século XIX. O nome Guaianá foi utilizado juntamente com outros nomes, por exemplo, Coroado, até que a denominação Kaingang passou a ser utilizada e difundida em documentos e na literatura. Através do livro "Jungle People: A Kaingang tribe of the highlands of Brazil", do antropólogo americano Jules Henry (1964), a denominação Kaingang teve uma repercussão mundial; no entanto, nesta obra o autor atribuiu a mesma denominação para os índios da etnia Xokleng. Inicialmente, estas duas etnias foram classificadas como como uma só, apenas com dialetos diferentes, sendo os Xokleng denominados AweikomaKaingang em 1946 pelo antropólogo suíço Alfred Métraux no Handbook of South American Indians (STEWARD, 1963). Isto se deve à proximidade cultural e linguística entre as duas etnias, mas que se diferem em relação à cultura material, espiritual e principalmente na organização espacial, em que cada etnia desenvolveu o seu processo sociocultural específico, tornando-se relativamente diferenciado, sendo consideradas atualmente como duas etnias com um passado remoto semelhante (HICKS, 1966; URBAN, 1992; VEIGA, 1992).

Von Inhering (1904) realizou uma sistematização a partir de relatos de viajantes e 
indigenistas sobre a situação dos povos indígenas do Sul na época. Este autor organizou a profusão de nomes equivocadas aos grupos de índios do Estado do Paraná, fazendo um estudo específico para a etnia Kaingang e suas diversas denominações, afirmando a descendência do povo Guaianá e elaborando também uma classificação em dois grupos:

As tribos da família Gês, caraterizadas pelo crânio dolicocéfalo, ou mesocéfalo, pertencem todas á familia dos Guayanãs, cujo domínio no século XVI se estendia desde o Rio Grande do Sul e o norte da Argentina atravez de São Paulo e Rio de Janeiro até o sertão da Bahia. Os seus descendentes atuais dividem-se em dous grupos, um oriental e outro occidental. O primeiro é formado pelos Caingangs que actualmente vivem desde as Missões Argentinas e o planalto do Rio Grande do Sul até os Estados de Paraná e S. Paulo. O seu nome antigo de Guayanãs conservou-se apenas no oeste do Estado de S. Paulo, nos municipios de Itapeva, Faxina etc., sendo substituido no mais pelo de Coroados ou Bugres ou mesmo pelo de algumas tribos como de Cames no littoral de S. Paulo e de Xocrens no de Santa Catharina. O grupo occidental é formado pelos Ingaim e pelos Guayanãs do alto Paraná na zona comprehendida entre os rios Uruguai e Paraná. (IHERING, 1904, p. 44).

O padre jesuíta Carlos Teschauer, historiador e naturalista alemão que viajou ao Sul do Brasil em 1880, é outro autor da época que acredita na ancestralidade da etnia Kaingang com o grupo Guaianá que habitou o litoral paulista entre Angra dos Reis (Rio de Janeiro) e Cananeia (região do litoral Sul de São Paulo) no século XVI (BECKER, 1976). Teschauer assegura-se nas constatações realizadas por Gabriel Soares de Souza em 1587, as quais relatam a convivência dos índios Tamoyo e Carijó com os índios "Guaianazes", mas com a grafia "Goainazes":

Já fica dito como os Tamoyos são fronteiros do outro gentio, que se chamam os Goainazes, os quaes tem sua demarcação ao longo da costa por Angra dos Reis, e d`ahi até o rio do
Cananea, onde ficam visinhando com outra casta de gentios, que se chamam os Cárijos (SOUZA, 1851, p. 99).

Teschauer (1927) percorreu povoações de indígenas Kaingang de Cazeros e Nonohay (Rio Grande do Sul) coletando informações e apontamentos deixados por missionários, e acabou por refutar a classificação de grupos sugerida por Hermann von Ilhering, afirmando que os ancestrais Kaingang (os Guaianá) migraram para o Sul do país, não podendo estar presentes nas terras sulistas nos séculos XVI e XVII.

Então, de forma geral, a história de contato dos índios da etnia hoje conhecida como Kaingang e os colonizadores europeus do século XVI se torna difícil devido ao grande número de denominações de grupos indígenas descritas na literatura da época e dos séculos seguintes. De acordo com Salomon e Schwartz (1999), durante o período colonial, os ancestrais da etnia Kaingang estavam presentes nas extensas planícies do planalto interior, onde faziam acampamentos temporários e organizavam expedições de refúgio em florestas subtropicais e tropicais do Sul do Brasil, que se tornaram restritas com o avanço da expansão colônica.

Ainda no século XVI, este povo foi identificado por desenvolver uma tradição de resistência à dominação colonial, fazendo com que a maior parte dos portugueses não tivesse interesse pelos Guaianá (nome conhecido na época pelos colonos portugueses e também pelos padres jesuítas aos ancestrais da etnia Kaingang); mesmo assim, muitos desses indígenas foram escravizados pelos colonos; outros, inseridos na aldeia missionária pelos jesuítas. Apesar de a população indígena Guaianá ser considerada de pouca utilidade para os portugueses, por serem vistos como selvagens (Tapuia, Bugre), os ataques continuaram, e diversos índios foram escravizados. Isso acabou provocando intensos conflitos que resultaram, no final do século XVI, em um recuo de áreas de colonização europeia. Em 1640, quando os portugueses encontraram maiores dificuldades em escravizar os índios da etnia Guarani, voltaram a centrar-se nos índios Guaianá, os quais se mostravam ainda mais resistentes, tornando-se insatisfatórios como 
escravos (D’ANGELIS, 1984; SOUZA; BERNASKI, 2015; SALOMON; SCHWARTZ, 1999).

Existem muitas semelhanças entre os costumes dos Kaingang e os Guaianá, tais como serem nômades, terem a agricultura inexpressiva, a caça e a coleta como principal base econômica, o isolamento nas matas e o distanciamento das populações civilizadas. Outro exemplo é a semelhança encontrada por escritores entre algumas expressões, como descrito pelo Padre Teschauer (1927), sobre a semelhança na denominação para "o espírito dos mortos", sendo "veicupli" para os Kaingang e "acupli” para os Guaianá:

Para os Caingang [...] sobrevindo-lhes uma desgraça, attribuem-na á vingança dos máos espiritos, dizendo vaicupli, a alma, o espirito, e querem indicar com isso que o espirito do seu inimigo lhes causou o damno. Reconhece-se facilmente a superstição dos antigos Guayaná, que, [...], chamavam as almas dos defunctos acupli e accreditavam que estas se convertiam em demonios. (TESCHAUER, 1927, p. 46).

Pode-se considerar que os Kaingang são descendentes diretos dos Guaianá do período colonial, que conservaram até o século XIX os costumes e hábitos dos Tapuia. Segundo Monteiro (2001), não há dúvidas de que os Guaianá que aparecem nos documentos e nas fontes antigas são os ancestrais da etnia Kaingang, pois possuíam grande área de domínio territorial, indo até as fronteiras do Uruguai, Argentina e Paraguai, o que também confirma sua condição de seminomadismo. Porém, alguns autores discordam sobre esta relação ancestral.

Para o historiador Afonso Antônio de Freitas (1908), com base no território paulista, os antigos Guaianá não têm parentesco com os modernos Kaingang, sendo estes formados por agrupamentos heterogêneos, ou seja, de indivíduos de raças indígenas diversas. Primeiramente, Freitas baseia sua hipótese a partir das observações realizadas em 1867 por Von Martius (2009) em relação à diversidade fisionômica e linguística dos Kaingang, juntamente com o relatório realizado em 1906 pelo médico Geraldo Assis Moura em uma expedição científica sobre a exploração e o reconhecimento do Rio do Peixe. Neste relatório, encontra-se uma descrição de duas mulheres e um homem Kaingang que eram prisioneiros em uma fazenda, destacando que uma das mulheres tinha o rosto mais comprido e largo do que a outra da mesma tribo. A partir destas análises, Freitas sugere que os Kaingang não possuem uma unidade tribal entre eles; além disso, com base na arqueologia de cemitérios indígenas Guaianá e nas análises da nomenclatura topográfica da região Piratininguana/SP, chegou à conclusão de que os antigos Guaianá tinham parentesco com os grupos Tupi-guarani, e que os Kaingang não povoaram territórios paulistas.

Segundo o professor Monteiro (1984, p. 24 apud PINHEIRO, 1992, p. 56), os Guaianá tiveram estreita relação com grupos Tupinambá, podendo ter ocorrido uma troca cultural e territorial entre eles, o que pode explicar a hipótese de semelhança física entre os Guaianá e os Tupi sugerida por Freitas. Em relação à constatação de que uma das mulheres indígenas prisioneiras teria o rosto diferente da outra, insinuando uma heterogeneidade racial dos Kaingang, isso pode ser explicado pela prática que era exercida entre os indígenas Kaingang de raptar crianças pertencentes a outras tribos durante as guerras intertribais; assim, confirmam-se as observações de Assis Moura sobre as diferenças físicas entre os rostos das indígenas. Com essas considerações etnológicas, pode-se contradizer a hipótese de heterogeneidade racial sugerida por Freitas.

A dúvida sobre os Guaianá serem Tupi ou Tapuia era muito discutida no final do século XVIII, quando o Frei Gaspar da Madre de Deus afirmou serem os Guaianá (Tapuia) moradores da região paulista, quando, na chegada dos primeiros portugueses, foi confirmada a presença de índios Tupi. De acordo com Monteiro (1992b), em 1888 o advogado João Mendes de Almeida afirmou, em uma sessão solene da Sociedade dos Homens de Letras de São Paulo, que os antigos moradores paulistas não eram Guaianá. A partir disso, muitos estudiosos começaram a contestar esta posição, como o historiador Capistrano de Abreu, que defendeu a sugestão de que os Guaianá da documentação antiga 
seriam os ancestrais dos modernos Kaingang, não configurando então o grupo Tupi. Assim, ambos os lados foram representados por intelectuais que buscavam apresentar as suas hipóteses de origem para esta população com o objetivo de tentar construir a identidade histórica paulista dentro do contexto na Nova República, além da necessidade da formulação de projetos e de políticas para o futuro dos índios (PREZIA, 1998).

No contexto ideológico da época, discutir a origem Tupi ou Tapuia dos indígenas Kaingang paulistas era uma questão polêmica, pois iria mostrar a descendência direta ou indireta de muitas famílias, e o paradigma Tupi-Tapuia indicavam a ambivalência da percepção que os europeus tinham em relação aos índios, ou era bondoso e feliz, ou selvagem e bárbaro. A discussão sobre as origens e ao passado da etnia Kaingang está presente em várias outras documentações, como memórias e crônicas realizadas no período colonial, como nas obras de Sebastião da Rocha Pita, Pedro Taques de Almeida Pais Leme, Simão de Vasconcelos, Frei Gaspar da Medre de Deus, e outros. Já na era da República, estudos etnográficos e históricos feitos por Joaquim Antônio Pinto Júnior, José Arouche de Toledo Rondon, José Joaquim Machado de Oliveira, José Bonifácio, apresentavam uma discussão em relação aos meios de incorporação dos índios à nação brasileira e no pensamento histórico paulista (MONTEIRO, 2001).

\section{Considerações finais}

Diante da distância secular existente entre os Guaianá do século XVI e os Kaingang do século XIX, e das decorrentes transformações históricas presentes, percebe-se a dificuldade dos pesquisadores em evidenciar a ancestralidade direta da etnia Kaingang com os Guaianá. Considerase mais provável essa ancestralidade, com base nas inúmeras pesquisas e em estudos sustentados pelas evidências documentais dos séculos passados (mapas, livros, relatos, cartas régias etc.) realizadas por cientistas, historiadores, aventureiros e viajantes que estiveram na região Sul do país. Apesar do rico material existente na literatura etnológica sobre os indígenas da etnia Kaingang, necessita-se de estudos etnográficos com maiores detalhes, que possam confirmar essa proximidade étnica. Além disso, deve-se procurar responder algumas dúvidas sobre (1) a sua origem, (2) como se deu o deslocamento espacial da etnia, (3) saber até que regiões estavam presentes, (4) quais os critérios foram utilizados para o seu deslocamento periódico, se, conforme os autores citados, esses indígenas se deslocaram do Sul para o Norte, ou conforme outros, se migraram de São Paulo para o Sul, como fuga do contato com os colonizadores (PINHEIRO, 1992).

Existe, de fato, uma limitação na literatura etnográfica para a cultura Kaingang ao compará-la com as demais etnias brasileiras, por exemplo, as da região Norte. E isto pode ter ocorrido pelo fato de esta etnia ser resultado de uma população que foi reconstruída a partir de uma sociedade que sofreu um processo rápido de desintegração, destacado também pelo marcante histórico de lutas pelo direito às suas terras (SALOMON; SCHWARTZ, 1999). Depois de conquistada, a população Kaingang foi obrigada a reorganizar-se em novos alicerces materiais e simbólicos, e criar estratégias para recuperar e reestruturar a sua especificidade sociocultural (TOMMASINO, 1995). A cada território invadido, os conquistadores davam novos nomes em português para as populações ali presentes, e a designação Coroados ou até mesmo Bugre no lugar da autodenominação Kaingang, fez com que estes indígenas insistissem em ser chamados de Kaingang, situação que ultrapassa os marcos dos estudos etimológicos e linguísticos. Assim, destaca-se, para além do grande histórico de luta e resistência contra a invasão de suas terras e a sua disseminação na nação brasileira, a luta dos Kaingang pela sua autodenominação (MOTA, 2004).

Esta breve historiografia sobre a ancestralidade Kaingang faz a revisão do que se sabe sobre a história e a origem desta etnia indígena, e, consequentemente, sobre sua cultura, seus costumes e sua organização social e política, como parte de um projeto mais vasto que visa à abordagem da etnociência desta etnia em uma perspectiva educacional. 


\section{Notas}

1 Os trechos foram mantidos sem correções à grafia original. Como a ortografia da época era diferente da atual, quaisquer desvios da norma culta devem ser desconsiderados.

\section{Referências}

BECKER, Ítala Irene Basile. O índio kaingang no Rio Grande do Sul. São Leopoldo: Unisinos, 1976.

BORBA, Telêmaco. Actualidade Indígena (Paraná, Brasil). Curitiba: Impressora Paranaense, 1908.

CASAL, Padre Manuel Aires de. A Corografia Brazilica ou Relação historico-geografica do Reino do Brazil: composta e dedicada a Sua Magestade fidelissima. vol. 2. Rio de Janeiro: Na Impressão Regia, 1817.

D’ANGELIS, Wilmar da Rocha. Toldo Chimbangue: história e luta Kaingang em Santa Catarina. Xanxerê: Cimi-Regional Sul, 1984.

D’ANGELIS, Wilmar da Rocha. Para uma história dos índios do oeste catarinense. Cadernos do CEOM: 20 anos de memórias e histórias, v. 19, n. 23, p. 265-343, 2006.

DORNELLES, Soraia Sales. De Coroados a Kaingang: as experiências vividas pelos indígenas no contexto de imigração alemã e italiana no rio Grande do Sul do século XIX e início do XX. 2011, 134 f. Dissertação (Mestrado em História) - Programa de Pós-Graduação em História, Universidade Federal do Rio Grande do Sul, Porto Alegre, 2011.

EMMERICH, Charlotte; MONSERRAT, Ruth. Sobre os Aimorés, Kreins e os Botocudos. Notas Linguísticas. In: BOLETIM DO MUSEU DO ÍNDIO. Antropologia, n. 3. Rio de Janeiro: Fundação Nacional do Índio, 1975. p. 3-44.

FREITAS, Afonso Antônio de. Os Caingangues de São Paulo. Revista do Instituto Histórico e Geográfico de São Paulo, n. 13, p. 361-395, 1908.
GUISARD, Luís Augusto de Mola. O bugre, um João-Ninguém. São Paulo em Perspectiva, v. 13, n. 14, p. 92-99, 1999.

HELM, Cecília Maria Vieira. Kaingáng, Guarani e Xetá na istoriografia paranaense. In: XIX Reunião Anual da ANPOCS, 19., 17-21 out. 1995. Caxambú. Anais... Caxambú: ANPOCS, 1995. p. 28.

HENRY, Jules. Jungle People: A Kaingang tribe of the highlands of Brazil. New York: Vintage Books, 1964.

HICKS, David. The Kaingang and the Aweikoma: A Cultural Contrast. Anthropos, v. 61, p. 839-846, 1966.

IHERING, Hermann von. Os Guayanãs e Caingangs de São Paulo. Revista do Museu Paulista, v. 6, p. $23-44,1904$.

LAGUE, May Mabilde. Apontamentos sobre os indígenas selvagens da Nação Coroados dos matos da Província do Rio Grande do Sul - 1836-1866. São Paulo: Ibrasa; Brasília: IN/Fundação Nacional Pró-Memória, 1983.

MARTIUS, Carl Friedrich Philipp von. Beiträge zur Ethnographie und Sprachenkunde Amerika's zumal Brasiliens. vol. 1. New York: Cambridge University Press, 2009.

MONTEIRO, John Manuel. Tupis, tapuias e historiadores: estudos de história indígena e do indigenismo. 2001. 233 f. Tese (Livre Docência) Universidade de Campinas, Instituto de Filosofia e Ciências Humanas, Campinas, SP. Disponível em: http://www.repositorio.unicamp.br/handle/ REPOSIP/281350 Acesso em: 07 mai. 2019.

MONTEIRO, John Manuel. Os Guarani e a história do Brasil meridional - Séculos XVI-XVII. In: CUNHA, Manuela Carneiro da (Org.). Histórias dos Índios no Brasil. 2. São Paulo: Schwarcz LTDA, 1992a. p. 475-498.

MONTEIRO, John Manuel. Tupis, tapuias e a história de São Paulo: revisitando a velha questão Guaianá. Novos Estudos, v. 34, p. 125- 185, 1992 b. 
MOTA, Lúcio Tadeu. A denominação Kaingang na literatura antropológica, histórica e linguística. In: TOMMASINO, Kimiye; MOTA, Lúcio Tadeu e NOELLI, Francisco Silva. Novas contribuições aos estudos interdisciplinares dos Kaingang. Londrina: UEL, 2004. p. 3-16.

MOTA, Lúcio Tadeu. As guerras dos índios Kaingang: A história épica dos índios Kaingang no Paraná (1769-1924). Maringá: EDUEM, 2008.

National Museum of Denmark. En fyrstelig gave Albert Eckhout: de første portraetter fra brasiliense. Disponível em: https://natmus.dk/fileadmin/ user_upload/natmus/undervisning/dokumenter/ etnografisk_samling/eckhout_gym.pdf. Acesso em: $18 \mathrm{dez} .2018$.

NEUWIED, Príncipe Maximiliano von WIED. Viagem ao Brasil nos anos de 1815 a 1817. Tradução de Edgar Sussekind de Mendonça e Flávio Poppe de Figueiredo. São Paulo: Companhia Editora Nacional, 1940.

NIMUENDAJÚ, Curt. Social organization and beliefs of the Botocudo of Eastern Brazil. Southwestern Journal of Anthropology, v. 2, n. 1, p. 93-115, 1946.

OLMEDILlA, Juan de la Cruz Cano y. Mapa Geografico De America Meridional. Madri, 1775. Disponível em: https://www.davidrumsey.com/ luna/servlet/detail/RUMSEY 8 1 240074 55122 97:Composite---Sheets-1-8--Mapa-. Acesso em: 29 nov. 2018.

PINHEIRO, Niminon Suzel. Os nômades. Etnohistória Kaingang e seu contexto: São Paulo, 1850-1912. 1992. 146 f. Dissertação (Mestrado em História) - Programa de Pós-Graduação em História, Universidade Estadual Paulista, Assis, 1992.

PREZIA, Benedito Antonio Genofre. Os Guaianá de São Paulo: uma contribuição ao debate. Revista do Museu de Arqueologia e Etnologia, São Paulo, v. 8, p. 155-177, 1998.

SAINT-HILAIRE, August. Viagem a Comarca de Curitiba (1820). Vol. 315. São Paulo: Brasiliana, 1964.
SALOMON, Frank; SCHWARTZ, Stuart B. The Cambridge history of the native peoples of the Americas. Madri: Cambridge University Press, 1999.

SCHMID, Philip. Coroado. Acervo da Biblioteca Nacional Digital - Brasil. Muenchen [Alemanha]: Gedruckt bei M. Lindauer, 1823-1831, 1 grav, litografia, pb, 46 x 59. Disponível em: http:// objdigital.bn.br/acervo_digital/div_iconografia/ icon1250074/icon1250074_11.jpg. Acesso em: 29 nov. 2018.

SISTEMA DE INFORMAÇÃO DA ATENÇÃO À SAÚDE INDÍGENA (SIASI). Portal do Ministério da Saúde (Brasil). 2014. Disponível em: http:// portalms.saude.gov.br/saude-indigena/gestao/siasi. Acesso em: 10 mar. 2019.

SOUZA, Gabriel Soares de. Tratado descriptivo do Brazil em 1587. Rio de Janeiro: Typographia Universal de Laemmert, 1851.

SOUZA, Almir Antonio de. Um viajante no Brasil Joanino: Auguste de Saint-Hilaire, o caminho das tropas, o mato e o campo, e os índios do planalto meridional. Mneme (Caicó), v. 15, p. 137-165, 2014.

SOUZA, Almir Antonio de. Armas, pólvora e chumbo: a expansão luso-brasileira e os indígenas do planalto meridional na primeira metade do século XIX. 2012. 420 f. Tese (Doutorado em História) - Programa de Pós-Graduação em História, Universidade Federal de Santa Catarina, Florianópolis, 2012.

SOUZA, Almir Antonio de; BERNASKI, Joice. O capitão comandante dos índios - Vitorino Condá, nos campos de Palmas, no Iranin e no Chapeco: os Kaingang e as terras indígenas do planalto meridional no Século XIX (1839-1844). Cadernos do CEOM, v. 28, p. 97-104, 2015.

STADEN, Hans. Viagem ao Brasil (versão do texto de Marpurgo, 1557). Rio de Janeiro: Officina Industrial Graphica, 1930.

STEWARD, Julian H. Handbook of South American Indians. New York: Cooper Square Publishers, 1963. 
TESCHAUER, Carlos. Os Caingangs ou Coroados no Rio Grande do Sul. Boletim do Museu Nacional, v. III, n. 3, p. 37-56, 1927.

TOMMASINO, Kimiye. A história dos Kaingang da bacia do Tibagi: Uma sociedade Jê Meridional em movimento. 1995. 351f. Tese (Doutorado em Antropologia) - Programa de Pós-Graduação em Antropologia, Universidade de São Paulo, São Paulo, 1995.

URBAN, Greg. A história da cultura brasileira segundo as línguas nativas. In: CUNHA, Manuela Carneiro da (Org.). História dos índios no Brasil. São Paulo: Companhia das Letras; Secretaria Municipal de Cultura; FAPESP, 1992. p. 87-102.

VARNHAGEN, Francisco Adolfo de. História Geral do Brasil. Rio de Janeiro: Laemmert, 1877.

VEIGA, Juracilda. Revisão bibliográfica crítica sobre organização social Kaingang. Cadernos do
CEOM: 20 anos de memórias e histórias, v. 19, n. 23, p. 259-332, 1992.

VEIGA, Juracilda. Organização social e cosmovisão Kaingang: uma introdução ao parentesco, casamento e nominação em uma sociedade Jê Meridional. 1994. 282 f. Dissertação (Mestrado em Antropologia Social) - Programa de Pós-Graduação em Antropologia Social, Universidade Estadual de Campinas, Campinas, 1994.

VEIGA, Juracilda. Cosmologia e práticas rituais Kaingang. 2000. 344 f. Tese (Doutorado em Antropologia) - Programa de Pós-Graduação em Antropologia, Universidade de Campinas, Campinas, 2000.

VIGNERON, Pierre Roche. Botocudos. Paris, França: Lith. de G. Engelmann, 1 grav, pb., 1835. Disponível em: http://objdigital.bn.br/acervo_ digital/div_iconografia/icon94994/icon94994_078. jpg. Acesso em: 21 set. 2018. 